Available online at GSC Online Press Directory

GSC Biological and Pharmaceutical Sciences

e-ISSN: 2581-3250, CODEN (USA): GBPSC2

Journal homepage: https://www.gsconlinepress.com/journals/gscbps

(RESEARCH ARTICLE)

\title{
In vitro antioxidant capacity and in vivo anti-ulcer and analgesic potentials of dichloromethane fraction of stem barks from Boswelli dalzielii Hutch
}

\author{
Konaté Kiessoun 1, 2, 4* , Mamounata Diao ${ }^{1}$, Crepin Dibala Ibingou ${ }^{1}$, Yomalan Kassi ${ }^{3}$, Alain Souza ${ }^{4}$ and Dicko \\ Mamoudou Hama ${ }^{1}$ \\ ${ }^{1}$ Laboratory of Food Biochemistry, Enzymology, Biotechnology and Bioinformatic, University of Ouagadougou, 03 \\ P.O.Box: 848, Ouagadougou 03, Burkina Faso. \\ ${ }^{2}$ Training and Research Unit in Applied and Technological Sciences, University of Dedougou, Burkina Faso. \\ ${ }^{3}$ Laboratory of Animal Physiology, UFR Bioscience, University of Felix Houphouet Boigny of Abidjan, 22 P.0. Box 582, \\ Abidjan 22, Ivory Cost. \\ ${ }^{4}$ Laboratory of Animal Physiology, Electrophysiology and Pharmacology, Faculty of Sciences, University of Science and \\ Technology of Masuku, Franceville, Gabon.
}

Publication history: Received on 24 March 2018; revised on 08 August 2018; accepted on 14 August 2018

Article DOI: https://doi.org/10.30574/gscbps.2018.4.3.0025

\begin{abstract}
The present study was conducted to study the in vitro antioxidant, antiulcer and analgesic activities of dichloromethane fraction (DCMF) of stem barks from Boswelli dalzielii Hutch using different models in rats and mice. The antioxidant activity has been evaluated using $\beta$-carotene-linoleic acid system and lipid peroxidation and which showed antioxidant capacities. Antiulcer activity of dichloromethane fraction (DCMF) of stem barks from Boswelli dalzielii Hutch was studied in rats by administration of ethanol-induced method and by pyloric ligation method. The analgesic activity of dichloromethane fraction (DCMF) of stem barks from Boswelli dalzielii Hutch (Burseraceae) was tested using the model of acetic acid induced writhing in mice. The present study exhibit maximum radical scavenging activity and has positive effects in a dose dependent manner against ulcer induced by pyloric ligation-induced ulcers and cytoprotective model and analgesic activity using the model of acetic acid induced writhing in mice. The obtained results allow justifying the traditional uses of Boswelli dalzielii Hutch. This present study has clearly supported the utilization of Boswelli dalzielii Hutch in Burkina Faso traditional medicine.
\end{abstract}

Keywords: Dichloromethane fraction; Stem barks; Boswelli dalzielii Hutch; Biological activities

\section{Introduction}

Oxidative stress is a consequence of imbalance between the production of reactive oxygen species (ROS) and antioxidants defense system of human body [1]. Many studies indicate that antioxidants systems have the ability to treat chronic metabolic disease by scavenging ROS due to oxidative stress systems [2]. Both enzymatic and non-enzymatic antioxidants need to protect organisms from inflammation caused by excessive generation of ROS like superoxide, hydroxyl, hydrogen peroxide and nitric oxide.

Peptic ulcer has unquestionably been a disease of the twentieth century. Epidemiological data for this disease and its complications have shown striking geographical variations in incidence and prevalence. There are different types of ulcers; most common are peptic ulcer, gastric ulcer which appeared to be due to damage to the lining of the stomach and duodenal ulcer, which was associated with excessive acid secretion by the stomach. The etiology of peptic ulcer was

\footnotetext{
${ }^{*}$ Corresponding author

E-mail address: mehekiessoum@yahoo.fr
}

Copyright (C) 2018 Author(s) retain the copyright of this article. This article is published under the terms of the Creative Commons Attribution Liscense 4.0. 
fiercely debated. It is believed that peptic ulcers developed due to an imbalance between aggressive factors (mucin, bicarbonate, prostaglandins) leading to an interruption in the mucosal integrity [3]. Gastric ulceration is a benign lesion on the mucosal epithelium upon exposure of the stomach to excess acid and aggressive pepsin activity [4]. It is the most prevalent gastrointestinal disorder ever known, accounting for an estimated 15 mortality out of every 15,000 complications yearly in the world [5]. The treatment of peptic ulcer is directed against reduction of aggressive factors or enhancement of mucosal defense of stomach and duodenum with cytoprotective agents. Endogenous non-protein sulfhydryl (SH) compounds are presumed to participate in gastric mucosal adaptive cytoprotection [6].

Analgesics are drugs that selectively relieve pain by acting on the central nervous system or peripheral pain mechanism without altering consciousness. Opioid and non-opioid analgesics are the most commonly employed agents for symptomatic relief of pain. Diclofenac is a phenyl acetic acid derivative belonging to the non-steroidal anti-inflammatory group (NSAIDs). It is relatively non-selective as a COX inhibitor [7]. It is the most commonly used NSAIDs which is approved for long term treatment of rheumatoid arthritis, osteoarthritis and ankylosing spondylitis. Its potency against COX-2 is substantially greater than that of indomethacin, naproxen or several other NSAIDs. NSAIDs provide effective management of pain and inflammation, but are associated with risk of peptic ulcer, hemorrhage and perforation [8]. Natural products are the major mine for discovering promising lead candidates of drug. They play an important role in future drug development programs. Since centuries, many plants are considered a fundamental source of potent analgesic drugs. Also, a number of drugs including proton pump inhibitors and $\mathrm{H} 2$ receptor antagonists are available for the treatment of gastric ulcer, but clinical evaluation of these drugs have shown incidence of relapses, side effects and drug interactions [9]. Thus, there is an urgent need to identify more effective and safe antiulcer agent. In this context, the use of medicinal plants for the prevention and treatment of different pathologies is in continuous expansion worldwide [10]. In order to enhance the use of plants as potential sources of new therapeutic agents and to advocate for effective treatment of diseases with fewer side effects, it is necessary to carry out pharmacological and toxicological studies on plants used by traditional healers. To contribute to this program of study, a plant used in the treatment of several diseases in the West Region of Burkina Faso caught our attention. This is Boswelli dalzielii Hutch belonging to the family Burseraceae and stem barks decoctions are commonly used in traditional medicine in the treatment of inflammation and gastric ulcer [11]. Previous studies have reported in evaluation of the aqueous extract of Boswelli dalzielii stem barks for antimicrobial activities and gastrointestinal effects [12] and Phytochemical analysis of this plant demonstrated the presence of saponosides, coumarins, steroids, tannins, polyphenols and flavonoids and alkaloids [11]. However, there is no data reported on antioxidant, antiulcer and analgesic activities of dichloromethane fraction (DCMF) of stem barks from Boswelli dalzielii Hutch. Considering the potential claims of this Burseraceae, the present study was undertaken to evaluate the ethnomedicinal use of Boswelli dalzielii Hutch (Burseraceae) in the treatment of ulcer in the order to provide scientific basis of the traditionally use of this Burseraceae.

\section{Material and methods}

\subsection{Plants material}

The vegetable materials (fresh stem barks) of Boswelli dalzielii Hutch (Burseraceae) were collected in November 2014 in Dedougou, $230 \mathrm{Km}$ West of Ouagadougou, capital of Burkina Faso. This plant was botanically identified by Dr. Traoré Lassina from the plants Biology Department of University Nobert Zongo from Koudougou.

\subsection{Preparation of aqueous acetone extract}

The field grown fresh samples (stem barks) were washed with tap water followed by distilled water to remove the adhering dust particles. After blotting, samples were air dried in shade. The dried plant materials (stem barks) were ground to fine powder and stored in clean air tight containers. A sample of $50 \mathrm{~g}$ of stem barks was placed in the Soxhlet and run by using $80 \%$ aqueous acetone $(500 \mathrm{ml})$ in $1 / 10$ ratio $(\mathrm{w} / \mathrm{v})$ for $24 \mathrm{~h}$ under mechanic agitation at room temperature. After filtration all the extracts were dried in vacuum rotary evaporator at $40^{\circ} \mathrm{C}$ under reduced pressure. Extracts were weighed and stored at $4{ }^{\circ} \mathrm{C}$ for further analysis.

\subsection{Extraction and fractionation}

Fifty grams of powdered plant material was extracted with $80 \%$ aqueous acetone (500 mL) in 1/10 ratio (w/v) for 24 h under mechanic agitation (SM 25 shaker, Edmund BÜHLER, Germany) at room temperature. After filtration, acetone was removed under reduced pressure in a rotary evaporator (BÜCHI, Rotavopor R-200, Switzeland) at approximately $40{ }^{\circ}$. The aqueous extracts were subjected to sequential liquid-liquid extraction with n-hexane, dichloromethane, ethyl acetate and n-butanol. Each fraction was then collected and concentrated to dryness under reduced pressure to obtain n-hexane fraction (n-HF), dichloromethane fraction (DCMF), ethyl acetate fraction (EAF) and n-butanol fraction. The 
different fractions were freeze-dried by Telstar Cryodos 50 freeze-dryer. The fraction residues were packed in water proof plastic flasks and stored at $4{ }^{\circ} \mathrm{C}$ until use.

\subsection{Animals handling}

Swiss NMRI mice (25-30 g) of both sexes were used for acute toxicity and Wister albino rats (180-240 g) of both sexes were used for anti-ulcer profile. All animals were housed in cages under controlled conditions of $12 \mathrm{~h} \mathrm{light/and} 12 \mathrm{~h}$ without light and $25^{\circ} \mathrm{C}$. They received pellets of food enriched with $20 \%$ protein and water ad libitum. They were deprived of food for $15 \mathrm{~h}$ (but with access to drinking water) and weighed before the experiments. Experiments on the animals were performed according to the protocols already approved by the Institute of Health Sciences Research/University of Ouagadougou (Burkina Faso) and met the international standards for animal study [13].

\subsection{Acute toxicity study}

Healthy male and female Swiss mice (25-30 g) were randomly divided into 7 groups ( 1 control group and 6 treated assay groups) of 6 animals ( 3 male and 3 female). The control group received water containing 10\% dimethyl sulfoxide (DMSO) administered intra-peritoneally. The water/acetone of extract of stem barks from Boswelli dalzielii Hutch (Burseraceae), suspended in 10\% DMSO was administered respectively intra-peritoneally at doses of $1 ; 2 ; 2.5 ; 3 ; 4 ; 5$ and $6 \mathrm{~g} / \mathrm{kg}$. The general behaviour of the mice was observed for $120 \mathrm{~min}$ after the treatment. The animals were observed for morbidity and mortality once a day for 14 days. The number of survivors after the 14 days period was noted. The toxicological effect was assessed on the basis of mortality for 14 days, which was expressed as the median lethal dose (LD50) (Lethal Dose 50) was estimated from the regression of log-probit mortality rate [14].

\subsection{In vitro antioxidant profiles}

\subsection{1. $\beta$-Carotene-linoleic acid assay}

The antioxidant activity of the dichloromethane fraction (DCMF) was evaluated using $\beta$-carotene-linoleic acid system according to [15]. In short, $1 \mathrm{~mL}$ of $\beta$-carotene solution in chloroform $(0.2 \mathrm{mg} / \mathrm{mL})$ was pipetted into a round-bottom flask. To the solution, $20 \mathrm{mg}$ of linoleic acid and $200 \mathrm{mg}$ of Tween 40 were added. After removing chloroform in a rotary evaporator, $50 \mathrm{ml}$ of aerated distilled water was added to the oily residue. Aliquots (5 ml) of thus obtained emulsion were transferred to a series of tubes containing $2 \mathrm{mg}$ of fraction or $0.5 \mathrm{mg}$ of butylated hydroxyanisol (BHA) (positive control). Emulsion without antioxidant served as control. After addition of the emulsion to the tubes, they were placed in a water bath at $50{ }^{\circ} \mathrm{C}$ for $2 \mathrm{~h}$. During that period, the absorbance of each sample was measured at $470 \mathrm{~nm}$ at 15 min intervals, starting immediately after sample preparation $(\mathrm{t}=0 \mathrm{~min})$ until the end of the experiment $(\mathrm{t}=120 \mathrm{~min})$. The rate of $\beta$-carotene bleaching $(\mathrm{R})$ for the fraction, BHA and water, was calculated according to first-order kinetics. The percent of antioxidant activity (ANT) was calculated as described in [16], using the equation:

$$
\mathrm{ANT}=\frac{R_{\text {control }}-R_{\text {sample }}}{R_{\text {control }}} \times 100
$$

Where $\mathrm{R}_{\text {control }}$ and $\mathrm{R}_{\text {sample }}$ are average bleaching rates of water control and antioxidant (flavonoids or BHA), respectively.

\subsubsection{Inhibition of lipid peroxidation}

Liver of male Wistar rats (160-180 g) was excised and homogenized (1\% w/v) in $0.154 \mathrm{~mol} / \mathrm{L} \mathrm{KCl} \mathrm{solution.} \mathrm{The}$ homogenate was centrifuged at $3000 \mathrm{rpm}$ at $4{ }^{\circ} \mathrm{C}$ for $10 \mathrm{~min}$ and supernatant was used for the assay. Peroxidation of the liver homogenate was induced by $\mathrm{FeCl}_{2}-\mathrm{H}_{2} \mathrm{O}_{2}$ [17]. Briefly, $1 \%$ liver homogenate was incubated with $0.5 \mathrm{mmol} / \mathrm{L}$ of each of $\mathrm{FeCl}_{2}$ and $\mathrm{H}_{2} \mathrm{O}_{2}$ with or without dichloromethane fraction (DCMF) $(50 \mu \mathrm{g} / \mathrm{mL})$. After incubation at $37{ }^{\circ} \mathrm{C}$ for 60 $\mathrm{min}$, the formation of malondialdehyde (MDA) was measured at $535 \mathrm{~nm}$ [17]. BHT served as positive control. The equation is:

$$
\text { Inhibition of peroxidation }(\%)=\frac{\mathrm{AC}-\mathrm{AA}}{\mathrm{AC}} \times 100
$$

Where AC is the absorbance of the control (without any treatment) and AA is the absorbance of the antioxidants. 


\subsection{In vivo biological activities}

After antioxidant activities, it revealed that dichloromethane fraction (DCMF) is the best fraction comparatively to the others. Therefore, our different activities should be evaluated with this fraction.

\subsubsection{Anti-ulcer potential of dichloromethane fraction (DCMF)}

Antisecretory evaluation: pyloric ligation-induced ulcers [18].

Four groups of albino Wistar rats $(\mathrm{n}=6)$ of both sexes were selected. In this model, Group 1 served as normal control (vehicle) received 0.5\% carboxymethyl cellulose (CMC), p. o., and Group 2 ranitidine (50 mg/kg, p. o.), whereas Groups 3 and 4 animals received dichloromethane fraction (DCMF) of stem barks from Boswelli dalzielii Hutch (Burseraceae) (200 and $300 \mathrm{mg} / \mathrm{kg}$, p. o. respectively) daily for 3 days. Animals were fasted overnight prior to start of the experiment, and were given water ad libitum. Pyloric ligation was applied by ligating the pyloric end of the stomach of rats on 3rd day under phenobarbital anaesthesia a dose of $35 \mathrm{mg} / \mathrm{kg} \mathrm{b.w.}$, after $30 \mathrm{~min}$ of fraction or ranitidine treatment. Animals were allowed to recover and stabilize in individual cage and were deprived of water during post-operative method, after $4 \mathrm{~h}$ of surgery. Rats were sacrificed with over dose of ether, stomach was removed and gastric juice was collected for performing gastric secretion study and ulcer scoring was done in stomach as described in the method of [19]. The gastric juice that was collected and centrifuged. The volume and $\mathrm{pH}$ was recorded and subjected to bio-chemical estimations like free acidity and total acidity. The ulcer score was divided by a factor of 10 to get the ulcer index. \% ulcer protection was calculated using Ulcer index values.

$$
\text { Ulcer index }=\frac{\text { Ulcer index in control }- \text { Ulcer index in test }}{\text { Ulcer index in control }} \times 100
$$

\section{Study of gastric fluid}

The various biochemical parameters like secretions viz, gastric volume, $\mathrm{pH}$, free and total acidity were evaluated.

\section{Gastric volume}

This was measured after centrifuging the gastric fluid; it was allowed to stand, decanted, and poured into the measuring cylinder of graduation $0.01 \mathrm{ml}$.

\section{Determination of $\mathrm{pH}$}

The $\mathrm{pH}$ of gastric juice was measuring using the PH meter (Cyber Scan, India).

Determination of free acidity and total acidity [20]

$1 \mathrm{ml}$ of gastric juice was pipetted into a $100 \mathrm{ml}$ conical flask. Two to three drops of Topfer's reagent were added and titrated with $0.01 \mathrm{~N}$ sodium hydroxide $(\mathrm{NaOH})$ which was previously standardized with $0.01 \mathrm{~N}$ of oxalic acid. Until all traces of the red colour disappears and the colour of the solution was yellowish orange. The volume of alkali was noted. This volume corresponds to free acid. Then 2 or 3 drops of phenolphthalein solution was added and titration was continued until a definite red tinge reappeared. Again the total volume of alkali added was noted. This volume corresponds to total acidity. Acidity was calculated by using the formula:

$$
\text { Acidity }=\frac{\text { Volume of } \mathrm{NaOH} \times \text { Actual Normality of } \mathrm{NaOH} \times 100 \mathrm{meq} / 1 \mathrm{t} / 100 \mathrm{~g}}{0.1}
$$

Cytoprotective model: ethanol-induced ulcer [21]

After $12 \mathrm{~h}$ of fasting, albino Wistar rats of both sexes were divided into four groups of six animals each. Group 1 served as normal control (vehicle) and received $0.5 \%$ Carboxyl methyl cellulose (CMC), and the group 2 was treated with Ranitidine (50 mg/kg). The groups 3 and 4 received 200 and $300 \mathrm{mg} / \mathrm{kg}$ of dichloromethane fraction (DCMF) of stem barks from Boswelli dalzielii Hutch (Burseraceae) respectively. All are administered orally. One hour after treatment, all rats received ethanol $(1 \mathrm{ml} / 200 \mathrm{mg} / \mathrm{kg}$, body weight) to induce gastric ulcer. After $4 \mathrm{~h}$ the animals were sacrificed by cervical dislocation, the stomachs were removed and opened along the greater curvature. Stomachs were gently rinsed with water to remove gastric contents and the mean ulcer index was calculated as described earlier [19]. 


\subsection{Analgesic activity}

The analgesic activity of dichloromethane fraction (DCMF) of stem barks from Boswelli dalzielii Hutch (Burseraceae) was tested using the model of acetic acid induced writhing in mice $[22,23]$. Experimental animals were randomly selected and divided into four groups denoted as group-I, group-II, group-III and group IV consisting of 5 mice in each group. Each group received a particular treatment i.e. control, positive control and one dose of the fraction. Group-I was served as the control and received only distilled water and tween-80. Group-II was received diclofenac sodium (25 $\mathrm{mg} / \mathrm{kg}$ of body weight, IP), the standard drug for comparison of potencies. The group-III was administered orally with dichloromethane fraction suspensions $(200 \mathrm{mg} / \mathrm{kg}$ of body weight) and the last group i.e. group-IV was administered orally with dichloromethane fraction suspensions ( $300 \mathrm{mg} / \mathrm{kg}$ of body weight). Thirty minutes interval was given to ensure proper absorption of the administered substances. Then the writhing inducing chemical, acetic acid solution $(0.7 \%, 10 \mathrm{ml} / \mathrm{kg})$ was administered intraperitoneally to each of the animals of a group [24]. After an interval of five minutes, which was given for absorption of acetic acid, number of squirms (writhing) was counted for 15 minutes. Number of writhes for each animal in all groups was recorded and the analgesic potency of the tested extract was determined as protection \% against writhing according to the following formula below:

$$
\text { (\%) Inhibition }=\frac{\text { Control mean }- \text { Treated mean }}{\text { Control mean }} \times 100
$$

\subsection{Statistical analysis}

Results were expressed as mean \pm SEM. Statistical significance was determined by one way analysis of variance (one way ANOVA) followed by Dunnett's t-test with level of significance set at $\mathrm{P}<0.05$.

\section{Results}

\subsection{Antioxidant potential}

\subsubsection{Antioxidant capacity of $\beta$-carotene-linoleic acid assay}

The basis of $\beta$-carotene-linoleic acid assay is degradation of $\beta$-carotene in reaction with linoleic acid free radical. Antioxidants present in the solution can hinder this reaction and consequently prevent discoloration of $\beta$-carotene solution. The reduction of absorbance of $\beta$-carotene-linoleic acid emulsion was showed in presence of the dichloromethane fraction (DCMF). Comparison of the ANT values of the samples (Figure 1) indicates that the dichloromethane fraction (DCMF) was less successful at inhibition of bleaching of $\beta$-carotene emulsion comparatively to BHA $(\mathrm{P}<0.05$ and $\mathrm{P}<0.001)$.

\subsubsection{Lipid peroxidation}

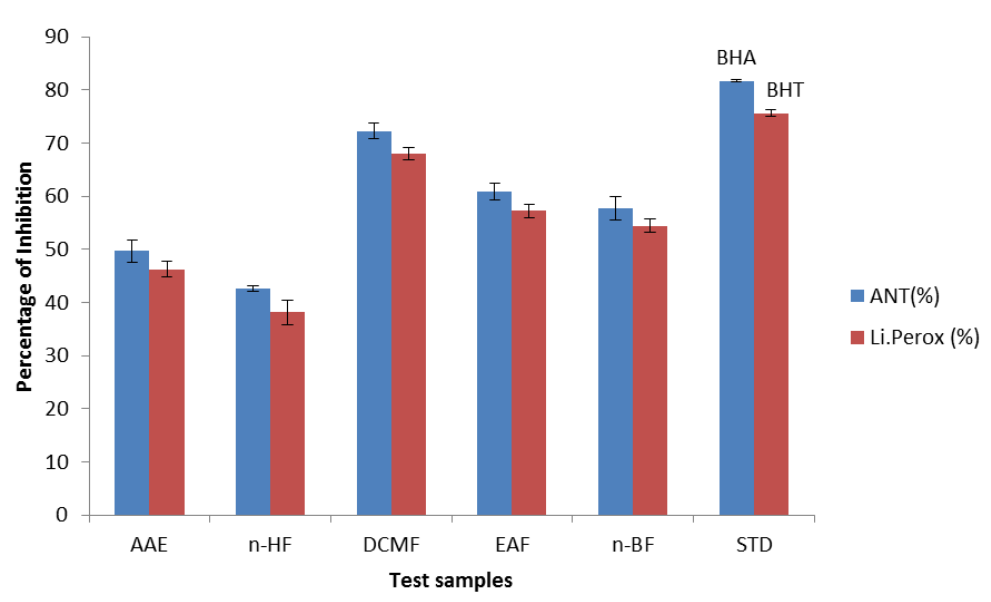

Figure 1 Antioxidant activity in $\beta$-carotene-linoleate test (ANT), and metal chelating activity of aqueous acetone extract, fractions and Standards (STD)

The endogenous basal of malondialdehyde in the rat liver homogenate was $40.02 \mathrm{mmol} / \mathrm{g}$ tissue. After $30 \mathrm{~min}$ of incubation $\mathrm{FeCl}_{2}-\mathrm{H}_{2} \mathrm{O}_{2}$, the incubation of malondaldehyde increase was measured at $535 \mathrm{~nm}$. The inhibition of lipid peroxidation activity by the dichloromethane fraction (DCMF) is presented in Figure 1. We noticed that 
dichloromethane fraction (DCMF) showed different statistically significant percentages of inhibition as compared to BHT $(\mathrm{P}<0.001$ and $\mathrm{P}<0.0001)$.

\subsection{In vivo biological activity}

\subsubsection{Acute toxicity study in mice}

The effect of intraperitoneal treatment of the aqueous acetone extract from Boswelli dalzielii Hutch (Burseraceae), on mortality, $\mathrm{LD}_{50}$ is $3270.8 \mathrm{mg} / \mathrm{Kg}$ body weight for intraperitoneal administration. No significant difference in body weight gain of the treated assay groups over the period of observation. No statistical difference was observed between the organ weights in the control and the intraperitoneal route groups.

\subsubsection{Pyloric ligation-induced ulcers}

The results of the ulcer score and effect of dichloromethane fraction (DCMF) from Boswelli dalzielii Hutch (Burseraceae) in Pylorus ligation model were shown in Table-1 and Table 2.

Table 1 Treatment schedule for ethanol-induced ulcers method

\begin{tabular}{clc}
\hline Sr. No. & Stomach colour & Ulcer score \\
\hline 1 & Normal colour & 0 \\
2 & Red colour & 0.5 \\
3 & Red spot & 1 \\
4 & Hemorrhagic streaks & 2 \\
5 & $3>5$ Ulcer & 2.5 \\
6 & $5>$ Ulcer & 3 \\
\hline
\end{tabular}

Table 2 indicated that fraction at the dose levels of $200 \mathrm{mg} / \mathrm{kg}$ and $300 \mathrm{mg} / \mathrm{kg}$ produced a significant decrease in the ulcer index, which was also evidenced by significant increase in percentage protection from ulcers at three the dose levels (76.87\% and $80.41 \%)$ respectively. The activity was comparable and equipotent with that of standard drug Ranitidine (85.14\%).

Table 2 Effect of dichloromethane fraction (DCMF) from Boswelli dalzielii Hutch (Burseraceae) on pylorus ligated rat model indicating ulcer index and percentage ulcer protection

\begin{tabular}{clll}
\hline Sr. No. & Treatment & Ulcer index & $\begin{array}{l}\text { Percentage of } \\
\text { Ulcer Protection }\end{array}$ \\
\hline 1 & Solvent control $(0.5 \% \mathrm{CMC}) 1 \mathrm{ml} / \mathrm{kg}$ & $60.02 \pm 0.60$ & - \\
2 & Ranitidine $(50 \mathrm{mg} / \mathrm{kg})$ & $8.92 \pm 0.47^{* *}$ & 85.14 \\
3 & fraction $(200 \mathrm{mg} / \mathrm{kg})$ & $13.88 \pm 0.51^{* *}$ & 76.87 \\
4 & Fraction $(300 \mathrm{mg} / \mathrm{kg})$ & $11.76 \pm 0.10^{* *}$ & 80.41 \\
\hline
\end{tabular}

Table 3 shows the results of gastric volume determination of dichloromethane fraction (DCMF) treated groups. It indicated that there was a significant decrease in the volume of the gastric juice. The activity was comparable and equipotent to that of Ranitidine $(\mathrm{P}<0.01)$. The results of gastric $\mathrm{pH}$ determination of dichloromethane fraction $(\mathrm{DCMF})$ (Table 3) treated groups indicated that there was a significant increase in the $\mathrm{pH}$ of the gastric juice. The activity was comparable and equipotent to that of Ranitidine $(\mathrm{P}<0.01)$. The results of free acidity and total acidity estimation of gastric juice of dichloromethane fraction (DCMF) (Table 3) treated groups indicated that there was a significant decrease in the free acidity and total acidity of the gastric juice when compared to control animals. 
Table 3 Effect of dichloromethane fraction (DCMF) from Boswelli dalzielii Hutch (Burseraceae) on pylorus ligated rat model indicating $\mathrm{pH}$, gastric volume, free acidity and total acidity of gastric juice

\begin{tabular}{|c|c|c|c|c|c|}
\hline $\begin{array}{l}\text { Sr. } \\
\text { No. }\end{array}$ & Treatment & $\begin{array}{l}\text { Gastric volume } \\
(\mathrm{ml})\end{array}$ & $\mathbf{p H}$ & $\begin{array}{l}\text { Free acidity } \\
(\mathrm{meq} / \mathrm{l} / \mathbf{1 0 0} \mathrm{g})\end{array}$ & $\begin{array}{l}\text { Total acidity } \\
\text { (meq/l/100 g) }\end{array}$ \\
\hline 1 & Solvent control $(0.5 \% \mathrm{CMC}) 1 \mathrm{ml} / \mathrm{kg}$ & $7.01 \pm 0.20$ & $4.02 \pm 0.24$ & $73.92 \pm 1.63$ & $133.02 \pm 1.63$ \\
\hline 2 & Ranitidine $(50 \mathrm{mg} / \mathrm{kg})$ & $4.92 \pm 0.19^{* *}$ & $4.12 \pm 0.20^{* *}$ & $43.88 \pm 1.10^{* *}$ & $97.86 \pm 1.57^{* *}$ \\
\hline 3 & Fraction $(200 \mathrm{mg} / \mathrm{kg})$ & $3.88 \pm 0.28^{* *}$ & $3.97 \pm 0.28^{*}$ & $49.02 \pm 1.57^{* *}$ & $94.01 \pm 1.15^{* *}$ \\
\hline 4 & Fraction $(300 \mathrm{mg} / \mathrm{kg})$ & $3.02 \pm 0.26^{* *}$ & $4.01 \pm 0.19^{* *}$ & $41.98 \pm 1.10^{* *}$ & $88.62 \pm 1.05^{* *}$ \\
\hline
\end{tabular}

\subsubsection{Cytoprotective model: ethanol-induced ulcer}

The effect of dichloromethane fraction (DCMF) from Boswelli dalzielii Hutch (Burseraceae) on ethanol induced ulceration model was shown in Table 4. The results showed that the tested extracts have protective activity for gastric mucosa, since at doses $200 \mathrm{mg} / \mathrm{kg}$ and $300 \mathrm{mg} / \mathrm{kg}$ of fractions. The results of ethanol induced ulceration model suggested that dichloromethane fraction (DCMF) at the dose levels of $200 \mathrm{mg} / \mathrm{kg}$ and $300 \mathrm{mg} / \mathrm{kg}$ produced a significant decrease in the ulcer index $(\mathrm{P}<0.01)$, which was also evidenced by significant increase in percentage protection from ulcers at the dose of $200 \mathrm{mg} / \mathrm{kg}$ and $300 \mathrm{mg} / \mathrm{kg}(77.06 \%$ and $79.73 \%)$ respectively. The activity at both the dose levels was comparable and equipotent to that of Ranitidine $(80.40 \%)$ treated group $(\mathrm{P}<0.01)$.

Table 4 Effect of dichloromethane fraction (DCMF) from Boswelli dalzielii Hutch (Burseraceae) on ethanol-induced ulcer model indicating ulcer index and percentage ulcer protection

\begin{tabular}{llll}
\hline $\begin{array}{l}\text { Sr. } \\
\text { No. }\end{array}$ & Treatment & Ulcer index & $\begin{array}{l}\text { Percentage of ulcer } \\
\text { protection }\end{array}$ \\
\hline 1 & Solvent control $(0.5 \% \mathrm{CMC}) 1 \mathrm{ml} / \mathrm{kg}$ & $91.88 \pm 0.20$ & \\
2 & Ranitidine $(50 \mathrm{mg} / \mathrm{kg})$ & $18.01 \pm 0.53^{* *}$ & 80.40 \\
3 & Fraction $(200 \mathrm{mg} / \mathrm{kg})$ & $21.07 \pm 1.10^{* *}$ & 77.06 \\
4 & Fraction $(300 \mathrm{mg} / \mathrm{kg})$ & $18.62 \pm 0.54^{* *}$ & 79.73 \\
\hline
\end{tabular}

Above value are mean \pm SEM; No. of animal in each group $=6$; ${ }^{*} \mathrm{P}$ - value $<0.05,{ }^{* *} \mathrm{p}$ value $<0.01$ compared with the corresponding control.

\subsubsection{Analgesic activity}

The effect of dichloromethane fraction (DCMF) from Boswelli dalzielii Hutch (Burseraceae) on acetic acid-induced writhing in mice. At dose of $200 \mathrm{mg} / \mathrm{kg}$ and $300 \mathrm{mg} / \mathrm{kg}$ of body weight, the dichloromethane fraction (DCMF) respectively produced $44.01 \%$ and $60.43 \%$ writhing inhibition in test animals (Table 5). The results were statistically significant $(P<0.001)$ and were comparable to the standard drug diclofenac sodium, which showed about $82.51 \%$ writhing inhibition at the dose of $25 \mathrm{mg} / \mathrm{kg}(P<0.001)$.

Table 5 Effect of dichloromethane fraction (DCMF) from Boswelli dalzielii Hutch (Burseraceae) on acetic acid induced writhing in mice

\begin{tabular}{llll}
\hline Treatment & $\begin{array}{l}\text { Number of } \\
\text { writhing }\end{array}$ & (\% Writhing) & $\begin{array}{l}\text { Inhibition } \\
\text { (\%) }\end{array}$ \\
\hline Group-I (Control) 1\% tween-80, 10 ml/kg, P.O. & $51.12 \pm 1.56$ & 100 & - \\
Group-II (Positive control) Diclofenac-Na, 25 mg/kg, P.O. & $8.94 \pm 1.19$ & 17.49 & 82.51 \\
Group-III (stem barks) DCMF 200 mg/kg, P.O. & $28.62 \pm 2.01$ & 55.98 & 44.01 \\
Group-IV (stem barks) DCMF 300 mg/kg, P.O. & $20.23 \pm 0.54$ & 39.57 & 60.43 \\
\hline
\end{tabular}

Above value are mean \pm SEM; ${ }^{* * *}$ p value $<0.001$ compared with the corresponding control. 


\section{Discussion}

Nowadays, it is noteworthy that traditional medicine is gaining popularity in developing countries. Medicinal plants are often believed to be harmless because they are natural and are commonly used for self-medication without supervision. This increase in popularity and the scarcity of scientific studies on their safety and efficacy have raised concerns regarding toxicity and adverse effects of these remedies [25]. These products of plants contain bioactive principles with the potential to cause adverse effects [26].

Free radicals are continuously generated and metabolized as the result of metabolic processes in the body and interact with the environmental stimuli. Under normal physiological conditions wide range of antioxidant defense mechanism protects the body against free radicals [27]. In normal conditions, the human body undergoes a number of the physiological and biochemical processes leads to the production of several radicals. Several researchers reported that natural herbs or plant based medicine could suppress the production of oxidative stress by increasing the antioxidants systems [28]. The activity might be due to the presence of phenolics compounds, carotenoids, vitamins, and terpenoids. These compounds have potency to scavenging the free radical in order to reduce the development of oxidative stress in many chronic diseases [29].

The ulcer is a major health hazard both in terms of morbidity and mortality. It is generally accepted that gastric ulcers result from an imbalance between aggressive factors and the maintenance of the mucosal integrity through the endogenous defense mechanism. The role of free radicals is also reported in the indication of ulcers. Prostaglandins (PG) offer protection to duodenum through both increases in mucosal resistance as well as the decrease in aggressive factors, mainly acid and pepsin. Ethanol-induced gastric ulcers have been widely used for the evaluation of the gastroprotective activity. Ethanol is metabolized in the body and releases superoxide anion and hydroperoxy free radicals. The incidence of ethanol-induced ulcers is predominant in the glandular part of the stomach. It was reported to stimulate the formation of leukotriene C4 (LTC4), mast cell secretory products and reactive oxygen species resulting in the damage of rat gastric mucosa. It has been found that oxygen-derived free radicals are implicated in the mechanism of acute and chronic ulceration in the gastric mucosa and scavenging these free radicals can play an appreciable role in healing these ulcers. Investigation of dichloromethane fraction (DCMF) from Boswelli dalzielii Hutch (Burseraceae) in the present study provides sample indications of its strong gastric anti-ulcerogenic property.

At acute toxicity level, the results showed that the plant extract did not cause any death at the end of the 14 days of experimentation. Moreover, some behavioral modifications that were observed after administration of extract at higher doses, returned to normal after 48h. According to [30], any product with LD50 higher than $5 \mathrm{~g} / \mathrm{kg}$ is regarded as nontoxic supporting the hypothesis that the extract might not be toxic. The drop in sensitivity and social interaction could be related to a depressive effect caused at the level of the central nervous system as previously mentioned by [31].

Gastric ulcer result of an imbalance between aggressive and defensive factors of the gastric mucosa factors [32]. To consolidate this balance, different therapeutic agents including medicinal plants are used to reduce gastric acid secretion or enhance mucosal defense mechanisms through increased mucus production [33]. This study was conducted to evaluate the preventive and curative properties of dichloromethane fraction (DCMF) from Boswelli dalzielii Hutch (Burseraceae) on gastric ulcer induced by ethanol. The results obtained from this work showed that dichloromethane fraction (DCMF) from Boswelli dalzielii Hutch (Burseraceae) significantly reduced the ulceration. Dichloromethane fraction (DCMF) from Boswelli dalzielii Hutch (Burseraceae) showed significant dose dependent ulcer protective effect against Pylorus ligation induced ulcers and Ethanol induced ulcers it was comparable to the standard drug Ranitidine. Moreover, gastric acid is an important factor for the genesis of ulceration in pylorus-ligated rats. The activation of the vagus-vagal reflux by stimulation of pressure receptors in the antra gastric mucosa in the hyper secretion model of pylorus ligature is believed to increase gastric acid secretion [33]. Our current data clearly demonstrated that, dichloromethane fraction (DCMF) from Boswelli dalzielii Hutch (Burseraceae) dose dependently decreased the gastric acid and pepsin secretion which showed antisecretory activity of dichloromethane fraction (DCMF) from Boswelli dalzielii Hutch (Burseraceae).The antiulcer activity of dichloromethane fraction (DCMF) from Boswelli dalzielii Hutch (Burseraceae) was detected in absolute ethanol-lesions in rats. These models evaluate the drug's capacity to protect the gastric mucosa, differentiating only the severity of gastric lesions. Ethanol-induced gastric damage may be due to stasis in gastric blood flow, which contributes to the development of the hemorrhagic and necrotic aspects of tissue injury. In addition, ethanol also induces solubilization of the mucus constituents, decreases the difference of potential in mucosa thus increasing the flow of $\mathrm{Na}^{+}$and $\mathrm{K}^{+}$to the lumen and pepsin secretion, and also increases $\mathrm{H}^{+}$ions and histamine [34]. The results showed that the fraction had an important protective activity for gastric mucosa, since at doses 200 and $300 \mathrm{mg} / \mathrm{kg}$ of fractions; they were effective in reducing ulcer lesions in the ethanol model. 
About the analgesic activity, it is well new that pain has been officially defined as an unpleasant sensory and emotional experience associated with actual or potential tissue damage. Pain acts as a warning signal against disturbances of the body and has a proactive function [35]. Analgesic activity of dichloromethane fraction (DCMF) from Boswelli dalzielii Hutch (Burseraceae) was tested by acetic acid induced writhing model in mice. Acetic acid-induced writhing model represents pain sensation by triggering localized inflammatory response. Acetic acid, which is used to induce writhing, causes algesia by liberation of endogenous substances, which in turn excite the pain nerve endings [36]. Increased levels of PGE2 and PGF2 $\alpha$ in the peritoneal fluid have been reported to be responsible for pain sensation caused by intraperitoneal administration of acetic acid [37]. Dichloromethane fraction (DCMF) from Boswelli dalzielii Hutch (Burseraceae) produced significant writhing inhibition comparable to the standard drug diclofenac sodium (Table 5). The polar compounds present in the plant extract may be responsible for the obtained analgesic activity. Based on this result, it can be concluded that the dichloromethane fraction (DCMF) from Boswelli dalzielii Hutch (Burseraceae) might possess analgesic activity.

\section{Conclusion}

In conclusion, the oral administration of dichloromethane fraction (DCMF) of stem barks from Boswelli dalzielii Hutch (Burseraceae) exhibits anti-ulcer activity in experimental ulcer models. The probable mechanism for its activity may be due to anti-secretary and cytoprotective properties.

\section{Compliance with ethical standards}

\section{Acknowledgments}

The authors thank Pr Karou of University of Lomé, Department of Biochemistry-Microbiology for the finalization of this manuscript article. Also, authors think Dr Traoré Lassina of University Nobert Zongo from Koudougou, for the botanically identified of plants.

\section{Disclosure of conflict of interest}

The authors have not declared any conflict of interests.

\section{Statement of ethical approval}

Ethical permission was taken in the Institute of Health Sciences Research/University of Ouagadougou (Burkina Faso) by authority of department of health sciences no [2007-01/MERSI/BF].

\section{References}

[1] Abuashwashi MA and Palomino OM. (2016). Geographic origin influences the phenolic composition and antioxidant potential of wild Crataegus monogyna from Spain. Pharmaceutical Biology, 54(11), $2708-2713$.

[2] Salem MB, Affes H, souda K, Dhouibi R, Sahnoun Z, Hammami S and Zeghal KM. (2015). Pharmacological studies of artichoke leaf extract and their health benefits. Plant Foods for Human Nutrition, 70(4), 441-453.

[3] Kaur Amandeep, Singh Robin, Sharma Ramica and Kumar Sunil. (2012). A review on etiology and pathogenesis. Research Journal of Pharmacy, 3(6), 34-38.

[4] Khazaei MandSalehi H. (2006). Protective effect of Falcaria vulgaris extract on ethanol induced gastric ulcer in rat. Iranian Journal Pharmacology and Therapeutics, 5(1), 43-46.

[5] Sonnenberg A. (1985). Geographic and temporal variations in the occurrence of peptic ulcer disease. Scandinavian Journal of Gastroenterology, 110, 11-24.

[6] Goel RK and Bhattacharya SK. (1991). Gastroduodenal mucosal defense and mucosal protective agents. Indian Journal of Experimental Biology, 29(8), 701- 714.

[7] Wagner W, Khanna P and Furst DE. (2004). Non-steroidal anti-inflammatory drugs, disease-modifying antirheumatic drugs, nonopioid analgesics, and drugs used in gout. Basic Clinical Pharmacology. $9^{\text {th }}$ ed., New York; Lange Medical Books/McGraw-Hill, 576-579.

[8] Mishra D, Ghosh GO, Kumar PS and Panda PK. (2011). An Experimental Study of Analgesic Activity of Selective COX-2 Inhibitor with Conventional NSAIDs. Asian Journal of Pharmaceutical Clinical and Research, 4(1), 78-81. 
[9] Reilly JP. (1999). Safety profile of the proton-pump inhibitors. American Journal Health System Pharmaceutical, 56 (4), S11-S17.

[10] Bighetti A, Antonio MA, Khon LK, Rehder VL, Foglio MA and Possendi A. (2005). Antiulcerogenic activity of a crude hydroalcoholic extract and coumarin isolated from Mikania laevigata Schultz Bip. Phytomedicine, 12, 727.

[11] Nacoulma OG. (1996). Medicinal plants and their traditional uses in Burkina Faso. PhD Thesis, University of Ouagadougou, 328.

[12] Nwinyi FC, Binda L, Ajoku GA, Aniagu SO, Enwerem NM, Orisadipe A, Kubarawa D and Gamanie IKS. (2004). Evaluation of the aqueous extract of Boswelli dalzielii stem bark for antimicrobial activities and gastrointestinal effects. African Journal of Biotechnology, 3(5), 284-288.

[13] Zimmermann M. (1983). Ethical guidelines for investigations of experimental pain in conscious animals. Pain, $16(2), 109-110$.

[14] Miller LC and Tainter ML. (1944). Estimation of the $\mathrm{LD}_{50}$ and its error by means of logarithmic probit graph paper. In Proceedings of the society for Experimental Biology and Medicine, 57, 261-264.

[15] Amarowicz R, Pegg RB, Rahimi-Moghaddam P, Barl B and Weil JA. (2004). Free-radical scavenging capacity and antioxidant activity of selected plant species from the Canadian prairies. Food Chemistry, 84, 551-562.

[16] Al-Saikhan MS, Howard LR and Miller JC. (1995). Antioxidant activity and total phenolics in different genotypes of potato (Solanum tuberosum L.). Journal of Food Science, 60, 341-347.

[17] Buege JA and Aust ST. (1978). Microsomal lipid peroxidation. Methods Enzymological, 52, 302-310.

[18] KokateCK, Khandelwal KR, Pawar AP and Gohalz SB. (1991). Practical pharmacognosy, Vallabh Prakashan, New Delhi.

[19] Shay M, Komarov SA, Fels D, Meranze D, Guenstein H and Siplet H. (1945). A simple method for the uniform production of gastric ulceration in the rat. Gastroenterology, 5, 43-61.

[20] Suzuki Y, Hayashi M, Ito M and Yamagami I. (1976). Antiulcer effects of 40-(2- carboxyethyl) phenyl trans-4aminomethyl cyclohexane carboxylate hydrochloride (Cetraxate) on various experimental gastric ulcers in rats.Japniaes Journal of Pharmacology, 26,471-480.

[21] Hawk PB, Oser BL and Summerson WH. (1947). Practical physiological chemistry. McGraw-Hill Book Company, New York, 375.

[22] Evans WC. (1989). Trease and Evan's textbook of pharmacognosy. Cambidge University Press, London, $13^{\text {th }}$ Edition.

[23] Ahmed F, Selim MST, Das AK and Choudhuri MSK. (2004). Anti-inflammatory and antinociceptive activities of Lipia nodiflora Linn. Pharmazie, 59, 329-330.

[24] Koster R, Anderson M and De-Beer EJ. (1959). Acetic acid for analgesic screening. Federation Proceedings, 18, 412-418.

[25] Saad B, Azaizeh H, Abu-Hijleh G and Said S. (2006). Safety of traditional Arab herbal medicine. Evidence-based Complementary and Alternative Medicine, 3(4), 433-439.

[26] Bent S and Ko R. (2004). Commonly used herbal medicines in the United States: a review. American Journal of Medicine, 116(7), 478-485.

[27] Halliwell B, Gutteridge JMC and Aruoma OI. (1989). The deoxyribose method: A simple test tube assay for determination of rate constants for hydroxyl radicals. Analytical Biochemistry, 165, 215-219

[28] Tohda C, Nakayama N, Hatanaka F and Komatsu K. (2006). Comparison of anti-inflammatory activities of six Curcuma rhizomes: a possible curcuminoid-independent pathway mediated by Curcuma phaeocaulis extract. Evidence-Based Complementary and Alternative Medicine, 3, 255-260.

[29] Goksel K, Murat K, Murat Y and Sevil M. (2008). Antioxidant activities of ethanol extracts of Hypericum triquetrifolium and Hypericum scabroides. Pharmaceutical Biology, 46, (4), 231-242.

[30] Atsamo AD, Nguelefack TB, Datte YJ and Kamanyi A. (2011). Acute and subchronic oral toxicity assessment of the aqueous extract from the stem bark of Erythrina senegalensis DC (Fabaceae) in rodents. Journal of Ethnopharmacology, 134, 697-702. 
[31] Ateufack G, Kamanyi A, Nguelefack T, Watcho P and Wansi SL. (2006). Antiulcer effects of aqueous and organic extracts of the stem bark of Anthocleista vogelii in rats. Pharmaceutical Biology, 44, 1-6.

[32] Salena BJ, Hunt RH. (2005). The stomach and the duodenum, in fundamentals of gastroenterology: pathological states and therapeutic approaches. $5^{\text {th }}$ Ed, Janssen-ortho, 158-198.

[33] Jainu M and Devi SS. (2006). Antiulcerogenic and ulcer healing effects of Solanum nigrum (L.) on experimental ulcer models: Possible mechanism for the inhibition of acid formation. Journal of Ethnopharmacology, 104, 156163.

[34] Witaicenis EF, Roldao LN, Seito NP and Di Stasi LC. (2007). Pharmacological and toxicological studies of Drimys angustifolia Miers. (Winteraceae). Journal of Ethnopharmacology, 111, 541-546.

[35] Tripathi KD. (1999). Essentials of medical pharmacology. $4^{\text {th }}$ Ed., Jaypee Brothers Medical Publishers (P) Ltd., New Delhi, India, 432.

[36] Taesotikul T, Panthong A, Kanjanapothi D, Verpoorte R and Scheffer JJC. (2003). Antiinflammatory, antipyretic and antinociceptive activities of Tabernaemontana pandacaqui Poir. Journal of Ethnopharmacology, 84, 31-33.

[37] Derardt, R, Jougney S, Delevalcee FandFalhout M. (1980). Release of prostaglandins E and F in an algogenic reaction and its inhibition. European Journal of Pharmacology, 51, 17-24.

\section{How to cite this article}

Konaté K, Mamounata D, Crepin DI, Yomalan K, Alain S and Dicko MH. (2018). In vitro antioxidant capacity and in vivo anti-ulcer and analgesic potentials of dichloromethane fraction of stem barks from Boswelli dalzielii Hutch. GSC Biological and Pharmaceutical Sciences, 4(3), 07-17. 